\title{
Characterization, Genetic Structure, and Pathogenicity of Rhizoctonia spp. Associated with Rice Sheath Diseases in India
}

\author{
Parissa Taheri, Sam Gnanamanickam, and Monica Höfte
}

First and third authors: Laboratory of Phytopathology, Faculty of Bioscience Engineering, Ghent University, Coupure Links 653, B-9000 Gent, Belgium; and second author: Center for Advanced Studies in Botany, University of Madras, Guindy Campus, Chennai 600025 , India. Accepted for publication 25 September 2006.

ABSTRACT

\begin{abstract}
Taheri, P., Gnanamanickam, S., and Höfte, M. 2007. Characterization, genetic structure, and pathogenicity of Rhizoctonia spp. associated with rice sheath diseases in India. Phytopathology 97:373-383.

Isolates of Rhizoctonia spp. were obtained from rice in India during 2000-2003. Characterization by conventional techniques and polymerase chain reaction showed that from 110 isolates, 99 were $R$. solani and 11 were $R$. oryzae-sativae. Of 99 isolates identified as $R$. solani, 96 were AG1-IA, 1 was AG1-IB, and 2 were AG1-IC. Amplified fragment length polymorphism (AFLP) analyzes were used to determine genetic relationships in Rhizoctonia pathogen populations collected from different geographic regions. Cluster analysis based on the AFLP data
\end{abstract}

separated isolates belonging to the three different intraspecific groups of $R$. solani AG1 and differentiated $R$. solani from $R$. oryzae-sativae. Analysis of molecular variance (AMOVA) revealed that geographic region was the dominant factor determining population structure of $R$. solani AG1-1A; host cultivar had no significant effect. Pathogenicity tests on Oryza sativa $\mathrm{cv}$. Zenith revealed that isolates of $R$. solani AG1-1A and AG1-1B were more virulent than $R$. solani AG1-IC and $R$. oryzae-sativae isolates.

Additional keywords: Ceratobasidium oryzae-sativae, genetic variability, rDNA-ITS region, Thanatephorus cucumeris.
Rhizoctonia sheath diseases of rice, comprising sheath blight, sheath spot, and aggregate sheath spot, cause significant yield losses in many rice-growing regions of the world $(14,16)$. The emergence of Rhizoctonia sheath diseases as economically important rice diseases is recent and has been attributed to the intensification of rice-cropping systems with the development of new short-stature, high-tillering, high-yielding varieties; high plant densities; and an increase in nitrogen fertilization. These factors promote disease spread by providing a favorable microclimate for Rhizoctonia spp., due to a denser leaf canopy with an increased leaf-to-leaf and leaf-to-sheath contact $(3,35)$.

Rice sheath blight, one of the most serious fungal diseases of rice, is caused by multinucleate $R$. solani Kühn [(teleomorph Thanatephorus cucumeris (A. B. Frank) Donk], a ubiquitous pathogen. Fourteen anastomosis groups (AGs) have been described in $R$. solani to date (4). Several anastomosis groups are further subdivided into intraspecific groups (ISGs). Isolates of AG1 have been divided into three ISGs, including IA, IB, and IC, based on host origin, symptoms, and cultural characteristics $(19,30,41)$. Isolates of AG1-IA have been associated with the development of rice sheath blight $(3,9)$. Sheath spot and aggregate sheath spot are caused by multinucleate $R$. oryzae Ryker \& Gooch (teleomorph Waitea circinata Warcup \& Talbot) and binucleate $R$. oryzae-sativae (Swada) Mordue (teleomorph Ceratobasidium oryzae-sativae Gunnell \& Webster), respectively. Both pathogens produce lesions on the leaf sheath very similar to those of sheath blight, and are known to occur in California, Argentina, and East Asia $(11,14)$. In addition to the similarity of disease symptoms,

Corresponding author: M. Höfte; E-mail address: monica.hofte@ugent.be

* The $\boldsymbol{e}$-Xtra logo stands for "electronic extra" and indicates that the online version contains a supplemental table showing binary data generated by amplified fragment length polymorphism (AFLP) of the 110 Rhizoctonia isolates represented in Figure 3.

DOI: 10.1094/PHYTO-97-3-0373

(C) 2007 The American Phytopathological Society distinguishing the various Rhizoctonia species in culture is difficult due to the lack of stable morphological characters on which to base a definitive classification of the genus Rhizoctonia and species assigned to it. Also, identification of the intraspecific groups of AG1 based on anastomosis grouping on a slide is not accurate because isolates of AG1-IA fuse well not only with other isolates of IA, but also with isolates of IB and IC (30).

Isolates of AG1-IA associated with rice sheath blight have been the subject of different diversity and population studies, in which variation has been measured using pathogenicity tests $(3,27)$, morphological characteristics (44), intra- and extracellular enzymes and proteins $(19,24,25,27,47)$, cellular fatty acids (43), and various molecular techniques such as restriction fragment length polymorphism (RFLP) $(3,34)$, simple sequence repeat polymerase chain reaction (SSR-PCR) (2), random amplified polymorphic DNA (RAPD) markers (28), and repetitive element PCR (Rep-PCR) (18). Previous investigations support the hypothesis that isolates of AG1-IA causing rice sheath blight display high genetic diversity $(2,34)$. In a recent population genetic study of $R$. solani AG1-IA from India that was based on RFLP and Rep-PCR, results were consistent with small genetic distances among populations and high levels of gene flow (18).

Knowledge of different populations of Rhizoctonia spp. causing rice sheath diseases in different geographic regions is still scarce. However, understanding of disease epidemiology and hostpathogen interactions is greatly dependent on knowledge of the diversity of the pathogen. Pathogen diversity can be studied using a wide array of techniques. However, the methods that have already been used to study rice sheath diseases often lack adequate discriminatory power and the reproducibility of some methods such as RAPD is poor (20). Consequently, it is necessary to establish highly sensitive and reliable genomic typing methods for Rhizoctonia isolates. The amplified fragment length polymorphism (AFLP) method is based on selective amplification of restriction fragments generated from total genomic DNA. The AFLP method generates dominant markers, which are less useful 
for studies that require precise assignment of allelic states, such as heterozygosity analyses. However, because of their rapidity, replicability, and high resolution, AFLP markers have emerged as a major type of genetic markers with a broad range of application, especially in analyzing genetic variation (26). AFLP fingerprinting has been shown to have potential for highresolution differentiation of genetically related $R$. solani AG-3 isolates from potato and tobacco (5). Also, the more loci that are screened, the lower the probability of making a mistake due to chance factors (20). Therefore, we investigated whether AFLP could be adapted for fingerprinting and genetic structure analysis of Rhizoctonia spp. isolates obtained from rice.

The objectives of the present study were to (i) characterize Rhizoctonia spp. associated with rice sheath diseases in India by morphological characterization and hyphal anastomosis in conjunction with molecular techniques, and to (ii) use AFLP markers to describe the genetic structure and relationships among Rhizoctonia spp. isolates from diverse rice cultivars and to study the dominant factors that determine population structure. In addition, inoculation of the isolates was done on Oryza sativa cv. Zenith, which is moderately susceptible to sheath blight (22), to investigate the variation in the virulence of different Rhizoctonia pathogens of rice identified in this study.

\section{MATERIALS AND METHODS}

Fungal isolates. A total of 300 Rhizoctonia spp. isolates, recovered from symptomatic rice tissues, were obtained from different rice cultivars in different rice growing areas in four states in India from 2000 to 2003 (Fig. 1). About one third of isolates collected from each location were selected randomly and subsequently used in this study. In total, a subset of 110 isolates was used (Table 1). Samples from each of 10 geographically defined rice-growing areas in India were collected using transect sampling by walking through the field diagonally. Per field, 10 samples were collected all along the path of the diagonal. A sample usually consisted of a single rice tiller, which either had sheath blight lesions on the sheath, on the leaf blades, or on both. Plant tissues of rice sheaths and leaf blades with sheath blight symptoms were surface-disinfected with $0.5 \%$ sodium hypochlorite solution for $2 \mathrm{~min}$ and rinsed three times with sterile distilled water. Then, pieces of sheath or leaf blade were dried on sterilized filter paper, placed on a petri dish containing acidified water agar (PH 4.5) with $10 \%$ lactic acid (AWA), and incubated at $28^{\circ} \mathrm{C}$ in the dark. After 2 to 3 days, cultures were examined microscopically for hyphal characteristics typical of Rhizoctonia spp. (39,41). All plated samples readily yielded Rhizoctonia spp., and a hyphal tip of each isolate was subcultured onto AWA for further purification. Isolates were transferred to potato dextrose agar (PDA) test tube slants and maintained at $28^{\circ} \mathrm{C}$. Following sufficient growth and production of sclerotia, culture tubes were kept at $4^{\circ} \mathrm{C}$ for short-term storage. Tester strains of $R$. solani AG1-IA (CSKA); AG1-IB (B19); AG1-IC (BV17); AG2-1 (PS4); AG2-2 IIIB (C96); AG2-2 IV (RI64); AG3 (ST-11-6); AG4-HG I (AH-1); AG4-HG II (Rh.165); AG5 (GM10); AG6-HG I (OHT-1); AG7 (HO-1556); and AG-BI (TS-2-4) were obtained from J. H. M. Schneider (ISR Sugar Beet Pathology/Pests, Bergen op Zoom, the Netherlands). For long-term storage of the isolates, one of the following methods was used: (i) culturing the fungus on sterile barley grains or (ii) storing lyophilized fungal mycelium or sclerotia at $4^{\circ} \mathrm{C}$.

Morphological characterization. Fungal isolates were initially characterized as either binucleate or multinucleate by the

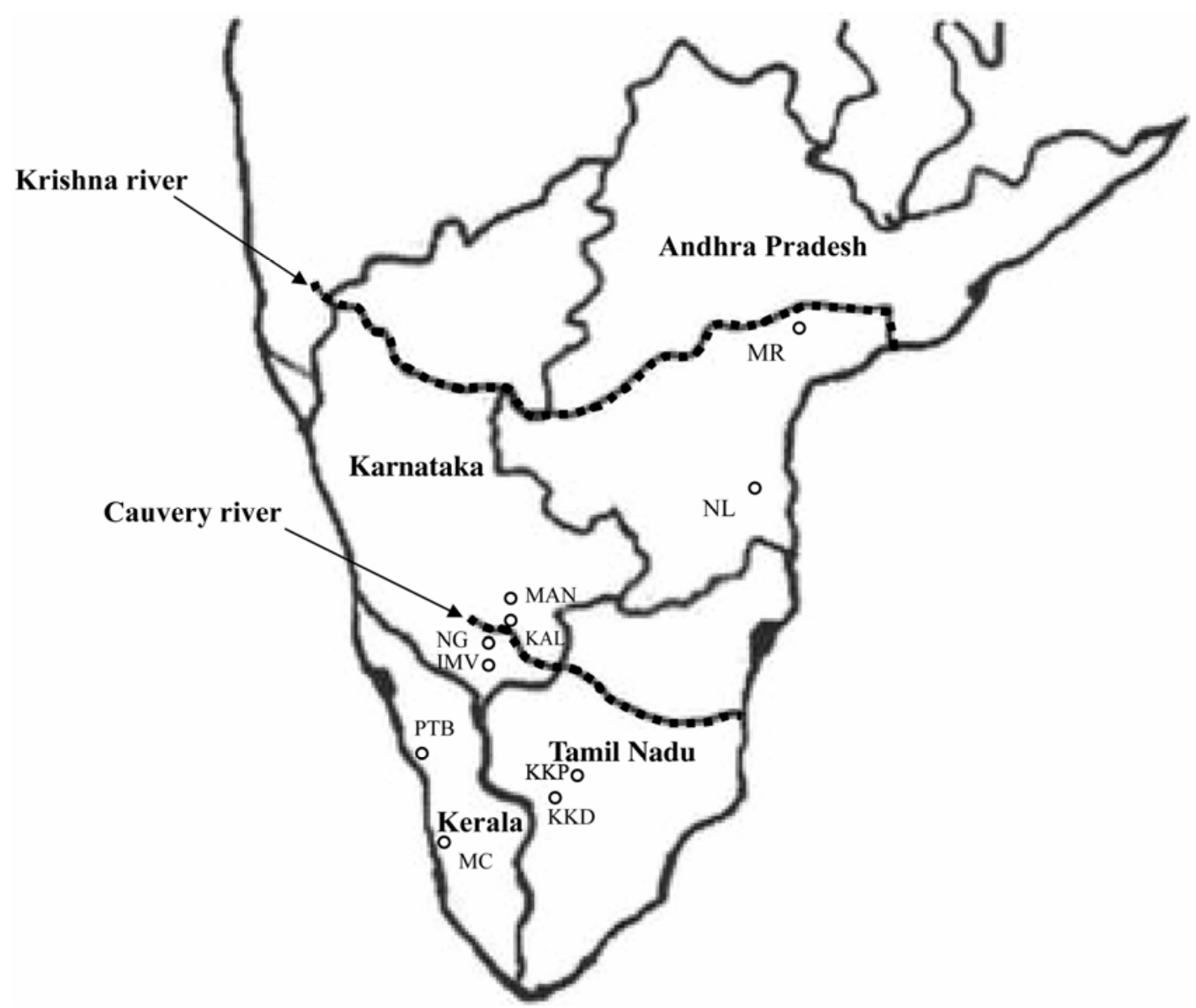

Fig. 1. Indian states from which isolates of Rhizoctonia spp. were sampled. Circles indicate the approximate locations. The two most widely separated sampling locations (MR and MC) were separated by $460 \mathrm{~km}$. 
trypan blue staining technique described by Martin and Lucas (23). Colonies of Rhizoctonia on PDA, 2 to 3 days old, were stained to determine nuclear number and were examined for the presence of a septal pore (dolipore) apparatus. The width of the main runner hyphae was investigated from the same preparations. Isolates were subcultured onto PDA petri dishes in triplicate, incubated at $28^{\circ} \mathrm{C}$ for 3 weeks, and compared for colony morphology and the size and shape of moniloid cells and sclerotia.

The reaction of isolates to phenol was tested on actively growing 5-day-old PDA cultures to investigate the presence of positive reaction to this compound (turning the color of mycelium dark brown in response to phenol) that is a special characteristic of $R$. oryzae isolates (15). A drop of lactophenol was placed directly on the mycelium at four locations equidistant between the center of the colony and the colony edge. Quadruplicate cultures were incubated in the dark for $48 \mathrm{~h}$ at $28^{\circ} \mathrm{C}$ before the reaction was evaluated.

DNA extraction. Cultures were grown at room temperature without shaking in 125-ml Erlenmeyer flasks containing $75 \mathrm{ml}$ of potato dextrose broth (PDB), 24 g/liter (Difco Laboratories, Detroit, MI). Mycelium was harvested after 5 days, preceding sclerotium formation. Lyophilized tissue was pulverized in liquid nitrogen. Total genomic DNA was extracted by the hexadecyltrimethylammonium bromide method according to Zolan and Pukkila (46). Total DNA was dissolved in 50 to $200 \mu \mathrm{l}$ of TrisEDTA (TE) buffer (10 mM Tris-HCl, $1 \mathrm{mM}$ EDTA, pH 8.0) depending on the size of the DNA pellet, and quantified by spectrophotometry. Dissolved DNA was stored at $-20^{\circ} \mathrm{C}$ until used.

PCR-based distinguishing of Rhizoctonia species and anastomosis typing. Rhizoctonia spp. isolates used in this study were distinguished using the PCR protocol described by Johanson et al. (14) using specific primers for PCR amplification (GMRS3/ITS1 for characterization of $R$. solani, GMROS-6/R635 for $R$. oryzae-sativae, and GMRO-3/R635 for $R$. oryzae) and conventional anastomosis typing (40).

PCR-RFLP of rDNA-ITS region. RFLP of rDNA-ITS was employed to clarify whether isolates of $R$. solani AG1 obtained from rice belonged to subgroup IA, IB, or IC. Tester strains of AG1-IA (CSKA) obtained from rice, and of AG1-IB (B19) and AG1-IC (BV17), both obtained from sugar beet, were included for comparison. Genomic DNA of the isolates was used for PCR amplification of the ITS region using a pair of primers, RS1 (5'-CCTGTGCACCTGTGAGACAG-3' and RS4 (5'-TGTCCAAGTCAATGGACTAT-3'), using the reaction conditions described by Guillemaut et al. (10). Restriction polymorphisms were detected using two discriminating restriction enzymes, MseI and MunI (MBI Fermentas, Vilnius, Lithuania) (10). Typical restriction enzyme reactions consisted of $7 \mu$ of PCR product, 10 units of restriction enzyme, $2 \mu$ l of reaction buffer, $0.2 \mu \mathrm{l}$ of bovine serum albumin, and $\mathrm{H}_{2} \mathrm{O}$ to a total volume of $20 \mu \mathrm{l}$. Reactions were incubated for $3 \mathrm{~h}$ at $37^{\circ} \mathrm{C}$ (or according to manufacturer's recommendations), then stopped by incubation at $70^{\circ} \mathrm{C}$ for $5 \mathrm{~min}$.

AFLP analysis. Genomic DNA was subjected to AFLP analysis based on the method described by Vos et al. (45) with minor modifications. All primers and adapters used in different steps were obtained from Proligo (Paris). AFLP templates were prepared by simultaneous digestion of approximately $500 \mathrm{ng}$ of DNA with EcoRI and MseI. Ligation of the restriction fragments to the adapters was performed in the same step. A 1:5 dilution of the restricted and adapter-ligated DNA was used as a template in the pre-amplification reactions. EcoRI and MseI primers without selective nucleotides $(E c o R I+0$ and $M s e I+0)$ were employed for pre-amplification. The pre-amplification products were quantified in a $1 \%$ agarose gel along with DNA marker. For the final selective amplification, the 1:10 diluted pre-amplified DNA was amplified using a $\gamma$ - $\left[{ }^{33} \mathrm{P}\right]$-ATP (Amersham Biosciences Europe, Roosendaal, the Netherlands) $5^{\prime}$ end labeled EcoRI- primer carrying two selective nucleotides (EcoRI + CA) in combination with a MseI-primer containing two selective nucleotides (either MseI + AT, MseI + CG, MseI + GC, or MseI + GT). Following amplification, an equal volume of formamide loading dye was added to the PCR products. After denaturation, the products were separated electrophoretically on $5 \%$ denaturing polyacrylamide gels, and bands were visualized using autoradiography. The SequaMark DNA size marker (Research Genetics, Huntsville, AL), ranging in size from 0.05 to $0.5 \mathrm{~kb}$, was used to determine fragment sizes. The reproducibility of the AFLP data was measured previously by repeating the entire procedure using one isolate from each ISG of $R$. solani AG1 (IA, IB, IC) and one isolate of $R$. oryzae-sativae.

Genetic relationships among Rhizoctonia spp. isolates. For each isolate, the DNA fingerprints were scored visually by considering 1 for the presence or 0 for the absence of specific AFLP bands. Only distinct, major, and very clear bands were scored. The correlation between the different genetic similarity matrices, obtained from the four separate primer pairs, was evaluated using NTSYS-pc program, version 2.10 L (Exeter Software, Setauket, NY). The DISTANCE ESTIMATION option of Treecon, version 1.3b (obtained from Ghent University, Bioinformatics and Evolutionary Genomics, Gent, Belgium) was used to calculate Nei and Li (29) similarity coefficients $\left(N_{\mathrm{s}}\right)$ among all pairs of isolates using the formula $N_{\mathrm{s}}=2 N_{\mathrm{xy}} /\left(N_{\mathrm{x}}+N_{\mathrm{y}}\right)$, where $N_{\mathrm{x}}$ is the number of markers amplified for isolate $X, N_{\mathrm{y}}$ is the number of markers amplified for isolate $Y$, and $N_{\mathrm{xy}}$ is the number of markers shared by isolates $X$ and $Y$. Additionally, genetic similarities based on the Nei and Li coefficient (29) and Jaccard's coefficient (13) were calculated using the SIMQUAL module of NTSYS-pc. Correlations between distance matrices obtained from the different primer combinations were evaluated by a Mantel Test (21) using the MXCOMP module of NTSYS-pc

TABLE 1. Designation of Rhizoctonia isolates used in this study

\begin{tabular}{|c|c|c|c|c|}
\hline State & Location & Year & Cultivar & Isolates \\
\hline $\begin{array}{l}\text { Andhra } \\
\text { Pradesh }\end{array}$ & Mertheru & 2001 & $\begin{array}{c}\text { Mukamala } \\
\text { IR-50 }\end{array}$ & $\begin{array}{l}\text { MR-1.1.2, 1.2.0, 1.1.6, } \\
1.2,1.44,1.43,1.98, \\
2.2,2.4,2.1,1.46,1.47, \\
1.92,1.73,1.80,1.83, \\
1.106,1.26,1.27 \\
\text { MR-1.4, } 1.35,1.37, \\
1.38,1.42,1.50 \\
\text { MR-1.32, } 1.48,1.87\end{array}$ \\
\hline $\begin{array}{l}\text { Andhra } \\
\text { Pradesh }\end{array}$ & Nellore & 2001 & $\begin{array}{l}\text { HR-12 } \\
\text { IR-50 }\end{array}$ & $\begin{array}{l}\text { NL-3, 10, 11, 51, 54, } \\
84,97,99,100,102 \\
\text { NL-18, 20, 30, 42, 44, } \\
70,104,105\end{array}$ \\
\hline $\begin{array}{l}\text { Karnataka } \\
\text { Karnataka }\end{array}$ & $\begin{array}{c}\text { Immavu } \\
\text { Nanjangudu }\end{array}$ & $\begin{array}{l}2000 \\
2000\end{array}$ & $\begin{array}{l}\text { Swarna } \\
\text { Swarna } \\
\text { HR-12 }\end{array}$ & $\begin{array}{l}\text { IMV-2.2, 3.0, } 3.3 \\
\text { NG-1.4, 1.5, 1.6,1.7 } \\
\text { NG-1.1, 1.3, } 1.8\end{array}$ \\
\hline Karnataka & Kalla & 2003 & $\begin{array}{l}\text { M. Vijaya } \\
\text { Sania }\end{array}$ & $\begin{array}{l}\text { KAL-34, 35, 36, } 65 \\
\text { KAL-29, 31, 32, 33, } 38\end{array}$ \\
\hline Karnataka & Mandiya & 2003 & $\begin{array}{c}\text { IR-50 } \\
\text { M. Vijaya }\end{array}$ & $\begin{array}{l}\text { MAN-38,40 } \\
\text { MAN-33, 43, 51, 79, } \\
86,87,88,89,90\end{array}$ \\
\hline Kerala & Moncombu & 2000 & $\begin{array}{c}\text { Neeraja } \\
\text { Pokkali-04 }\end{array}$ & $\begin{array}{l}\text { MC- } 1.8,1.32,16 \\
\text { MC- } 1.43,3.4,4.1\end{array}$ \\
\hline Kerala & Pattambi & 2000 & $\begin{array}{l}\text { Pavizham } \\
\text { PTB-9 }\end{array}$ & $\begin{array}{l}\text { PTB-3.6, 3.7, 3.12, } 5 \\
\text { PTB-8.7, 9.1, 20, 48, } \\
61\end{array}$ \\
\hline \multirow[t]{4}{*}{$\begin{array}{l}\text { Tamil } \\
\text { Nadu }\end{array}$} & $\begin{array}{l}\text { Keelkudal- } \\
\text { oor }\end{array}$ & 2000 & IR-20 & $\begin{array}{l}\text { KKD- } 1.4,1.5,1.12, \\
1.13,1.15,1.23,1.26 \text {, } \\
1.33,1.35\end{array}$ \\
\hline & $\begin{array}{c}\text { Keelaka- } \\
\text { manakanpat }\end{array}$ & 2000 & IR-20 & KKP-1.12, 1.15, 1.16 \\
\hline & & & IR-36 & $\begin{array}{l}\text { KKP- } 1.37,1.38,1.52 \text {, } \\
1.54,1.65\end{array}$ \\
\hline & & & ADT-24 & KKP-1.27, 1.28 \\
\hline
\end{tabular}


to analyze the complementarity or redundancy of the information. The generated similarity matrices were then analyzed using the various clustering methods of NTSYS-pc (SAHN module): UPGMA (unweighted pair group method with arithmetic average) (42), WPGMA (weighted pair group method) (40), complete linkage, and single linkage (17). All dendrograms were created with the TREE program of NTSYS-pc or the DRAW option of Treecon. The goodness of fit of the clustering to the data matrix was determined by calculating the cophenetic correlation coefficient between the similarity matrix and the cophenetic matrix derived from the dendrogram, using the COPH and MXCOMP procedures of the NTSYS-pc. Reliability of the dendrograms was tested by comparing dendrograms from different methods and by bootstrap analysis with 1,000 replications using Treecon. Some authors consider that confidence limits obtained in bootstrap must be over $95 \%$ in order to consider the grouping of isolates at a branch to be statistically significant (8). Others use a lower limit (50\% or higher) as indicating statistical support for the topology at a node (12). In this study the grouping of the isolates is considered as being statistically significant when the bootstrap values reached over $70 \%$.

Genetic structure of Rhizoctonia spp. populations from rice in India. The analysis of molecular variance (AMOVA) procedure (36) was used to compare groups of $R$. solani AG1-IA populations differing in geographic origin or host cultivar. Also, average gene diversity over loci in each population was calculated by AMOVA procedure. AMOVA calculations were conducted in Arlequin version 2.0 (obtained from the Genetics and Biometry Laboratory, Department of Anthropology, University of Geneva, Switzerland). AMOVA partitioned total variance into hierarchical components (among groups, among subgroups, and within subgroups). Nonparametric permutation of the data set was used to determine probability values and to test the significance of each covariance component. This statistical analysis is recognized as an effective tool to define population structure and degree of genetic differentiation (7).

Additionally, the Nei and Li (29) similarity matrix was used to calculate genetic similarity values between and within the different groups of isolates for comparing groups of $R$. solani AG1-IA isolates differing in geographic origin.

Pathogenicity tests. All $R$. solani AG1-1B, AG1-1C, and $R$. oryzae-sativae isolates and representative isolates of $R$. solani AG1-IA were inoculated into Oryza sativa cv. Zenith, which is moderately susceptible to sheath blight (22). Zenith seeds were obtained from the International Cooperation Center of Agricultural Research for Development (CIRAD) (Paris). Prior to testing, all isolates were passed through rice and re-isolated. Rice seeds were germinated in humid plates ( $\geq 95 \%$ room humidity) at $28^{\circ} \mathrm{C}$ for 4 days. Germinated seeds were sown in trays in potting compost (Klassmann-Deilman, Geeste, Germany) and grown under greenhouse conditions at $30 \pm 4^{\circ} \mathrm{C}$ with a $16 / 8 \mathrm{~h}$ light/dark photoperiod. Plants were fertilized at $8,15,22,29$, and 36 days with $5 \mathrm{~g}$ of $\left(\mathrm{NH}_{4}\right)_{2} \quad \mathrm{SO}_{4} \mathrm{~m}^{-2}$. Forty-two day-old plants were inoculated with inoculum consisting of toothpicks, $2 \mathrm{~cm}$ in length, that had been sterilized and inoculated with isolates of $R$. solani or $R$. oryzae-sativae $(31,32)$. After an incubation period of 8 days, one colonized toothpick was placed into the lowest inner sheath of the main tiller, $5 \mathrm{~cm}$ above the soil surface. For each isolate, eight replicate rice plants were inoculated in a completely randomized experimental design and the experiment was repeated twice. A noncolonized toothpick, which was placed on PDA without fungus, was used as a control for the pathogenicity tests. Immediately after inoculation, all plants were transferred to a plastic moist chamber with 92 to $100 \%$ humidity, inside a greenhouse. Disease severity was recorded 7 days after inoculation by determining relative lesion height using the formula ([highest point a lesion is seen/plant height] $\times 100$ ) described by Sharma et al. (37). Isolate identities were confirmed through re-isolation. Data were analyzed statistically, using the Kruskall-Wallis multiple comparison tests completed by a MannWhitney comparison test at $P=0.05$.

\section{RESULTS}

Morphological characterization. Of the 110 isolates recovered from rice sheath lesions in geographically different rice growing areas in India (Fig. 1, Table 1), 99 were multinucleate and 11 were binucleate. The number of nuclei per cell varied from 4 to 16 and the width of the main runner hyphae varied from 7 to $11 \mu \mathrm{m}$ for multinucleate isolates. All isolates of binucleate Rhizoctonia contained only two nuclei per hyphal cell and the width of the main runner hyphae varied from 4 to $6 \mu \mathrm{m}$. Of the 99 multinucleate Rhizoctonia isolates, 96 isolates corresponded to $R$. solani AG1 type 1 (AG1-IA), 1 isolate corresponded to AG1 type 2 (AG1-IB), and 2 isolates corresponded to AG1 type 3 (AG1-IC) in colony morphology and sclerotial type described by Sherwood (38). All 99 multinucleate Rhizoctonia isolates produced dark brown mycelium on PDA and barrel shaped moniloid cells (10 to $20 \times 20$ to $29 \mu \mathrm{m}$ ) that were isolated or in loose aggregates on aerial mycelium. Colonies of the 11 binucleate Rhizoctonia isolates on PDA were white initially but turned to pale brown within 3 weeks. These 11 isolates produced numerous spherical sclerotia on PDA that were approximately 0.20 to $0.90 \mathrm{~mm}$ in diameter. Sclerotia were white when young and became brown as they matured. Besides sclerotia, these fungi sometimes produced chains of elongate moniloid cells (6 to $10 \times 22$ to $30 \mu \mathrm{m})$ in aggregates on aerial hyphae. All Rhizoctonia isolates reacted negatively to phenol and the color of mycelium at the reaction point did not change. Therefore, there is no evidence for the presence of $R$. oryzae in our collection.

PCR-based distinguishing of Rhizoctonia species and anastomosis grouping. The rDNA-ITS region for 110 Rhizoctonia isolates was amplified using three primer combinations. The GMRS-3/ITS1 primer pair, which is specific for amplification of the rDNA-ITS region of $R$. solani, gave a single product of $0.55 \mathrm{~kb}$ for 99 multinucleate isolates only, and primer pair GMROS-6/R635, which is specific for identification of $R$. oryzae-sativae, gave a single product of $1.2 \mathrm{~kb}$ for 11 binucleate Rhizoctonia isolates only. Primer combination GMRO3/R635 (specific for characterization of $R$. oryzae) did not give any band for any Rhizoctonia isolate. Therefore, on this basis, the results of morphological characterization of Rhizoctonia isolates were confirmed and we identified two species of Rhizoctonia including $R$. solani (99 isolates) and $R$. oryzaesativae (11 isolates) in our collection.

All of the $99 R$. solani isolates anastomosed with the AG1-IA tester isolate and with the other ISGs of AG1, including IB and IC. When the binucleate KKD-1.33 ( $R$. oryzae-sativae) was used as tester, anastomosis occurred only with the binucleate $R$. oryzae-sativae isolates.

PCR-RFLP of rDNA-ITS region. The rDNA-ITS region, including ITS1, 5.8S, and ITS2 for 99 isolates of $R$. solani and the tester isolates of AG1-IA, AG1-IB, and AG1-IC, was amplified and digested using two discriminating restriction enzymes (MunI and MseI). The amplified fragment of AG1-IA showed no restriction site variation among AG1-IA isolates. However, the three ISGs of $R$. solani AG1 (IA, IB, and IC) differed from each other in restriction sites generated with MunI and MseI. Restriction fragments corresponding to a digestion by MunI were 0.2 and $0.31 \mathrm{~kb}$ for all AG1-IA isolates while AG1-IB and AG1IC isolates had no restriction site and showed a single fragment of $0.55 \mathrm{~kb}$ (Fig. 2A). Restriction fragments corresponding to a digestion by $M s e$ I consisted of two larger bands with similar sizes, approximately $0.2 \mathrm{~kb}$, for all AG1-IA, IB, and IC isolates including the testers. The smaller bands were 0.12 and $0.06 \mathrm{~kb}$ for 
AG1-IB and -IC isolates, respectively (Fig. 2B). In both cases (digestion with MunI or $\mathrm{MseI}$ ), restriction fragments less than $0.05 \mathrm{~kb}$ were not taken into consideration because they would not be clearly resolved by electrophoresis. The whole PCR-RFLP procedure was repeated twice with similar results.

AFLP analysis. A total of $64 E c o \mathrm{RI}+2 / M s e \mathrm{I}+2$ primer combinations were prescreened for their ability to detect polymorphisms in four selected isolates representing one $R$. oryzae-sativae genotype and three different ISGs of $R$. solani AG1 (IA, IB, and IC). Most selective primer combinations tested generated too many fragments for reliable scoring. Four primer pairs were selected (Table 2) based on the clarity of the bands obtained, the number of fragments amplified, and the polymorphism rate observed. These primer pairs were applied to the complete set of isolates listed in Table 1. The reproducibility of AFLP data was measured by repeating the entire procedure twice with four selected primer pairs, using one isolate from each ISG of $R$. solani AG1 (IA, IB, IC) and one isolate of $R$. oryzaesativae, with similar patterns. When bands from all of the isolates were considered, the four primer combinations used revealed a total of 443 bands, ranging in length from 0.05 to $0.5 \mathrm{~kb}$. From these fragments, 292 unambiguous (distinct and clear) bands were scored (Table 2). Only 37 bands were monomorphic across the complete set of isolates, resulting in $87 \%$ of the scored bands being polymorphic. Within the isolates of $R$. solani AG1-IA, the number of scored bands generated by individual primer pairs ranged from 50 to 90 . Of the 278 markers scored, 43 were shared by all $96 R$. solani AG1-IA isolates. As a result, the band polymorphism level within the AG1-IA isolates was $84 \%$.

Genetic relationships among Rhizoctonia spp. isolates. The dendrogram generated using Treecon with the Nei and Li (29) similarity coefficient based on 292 AFLP bands revealed the presence of two predominant clusters, joined by a single node at the $60 \%$ similarity level and supported by bootstrap values of $100 \%$ (Fig. 3). Cluster 1 contained $99 R$. solani isolates, clearly separated from cluster 2's $11 R$. oryzae-sativae isolates. Within cluster
1, three ISGs of $R$. solani AG1 isolates were distinguishable. All of the 96 AG1-IA isolates clustered together in group 1A, separated from $1 \mathrm{~B}$ (containing the single isolate of AG1-IB), and also clearly separated from group $1 \mathrm{C}$ (containing two isolates of AG1IC). Isolates of group 1A were linked to $1 \mathrm{~B}$ with $84 \%$ similarity, while $1 \mathrm{C}$ was linked to $1 \mathrm{~A}$ with $82 \%$ similarity (Fig. 3). At the $90 \%$ similarity level, three groups could be identified in $R$. solani AG1-IA and two groups in $R$. oryzae-sativae, supported by bootstrap values of 99 or $100 \%$ (Fig. 3). All isolates collected from Andhra Pradesh and KAL, and MAN isolates from Karnataka, clustered together in group 1Aa. IMV and NG isolates of Karnataka clustered in group 1Ac. All isolates of Kerala, except isolate MC-16, were placed in group $1 \mathrm{Ab}$; isolates collected from Tamil $\mathrm{Nadu}$ were placed in groups $1 \mathrm{Ab}$ and $1 \mathrm{Ac}$. In the $R$. oryzaesativae population, both groups $2 \mathrm{~A}$ and $2 \mathrm{~B}$ contained only isolates collected from Tamil Nadu (Fig. 3). There is some evidence of additional structure within AFLP groups 1Aa and 1Ac. Within group 1Aa, isolates from Andhra Pradesh grouped separately from the Karnataka isolates, although this was not supported by a high bootstrap value. Group 1Aa contained 14 unique clones (i.e., cases in which two or more isolates shared completely the same AFLP geno-type) among 66 total isolates. A few additional clones were found in groups $1 \mathrm{Ab}$ and $1 \mathrm{Ac}$. Among $R$. solani AG1-IA isolates, 18 clones were identified (Fig. 3). These clones represented $51 \%$ of the AG1-IA isolates. One clone was identified among isolates of $R$. oryzae-sativae (KKD-1.33/KKD-1.35). The same AFLP genotypes were found only in the populations of the same taxonomic group collected from the same location and in the same year, but from the same or different rice cultivars. Isolates of $R$. solani AG1-IA were found in all states, whereas AG1-IB and AG1-IC isoates were only found in Tamil Nadu and Kerala. Each AFLP group identified in the collection was associated with various rice cultivars except for group $2 \mathrm{~A}$, which was associated with a single rice cultivar, IR-20. Sixty-eight AFLP genotypes were identified among isolates of $R$. solani and 10 genotypes were identified among isolates of $R$. oryzae-sativae (Fig. 3).
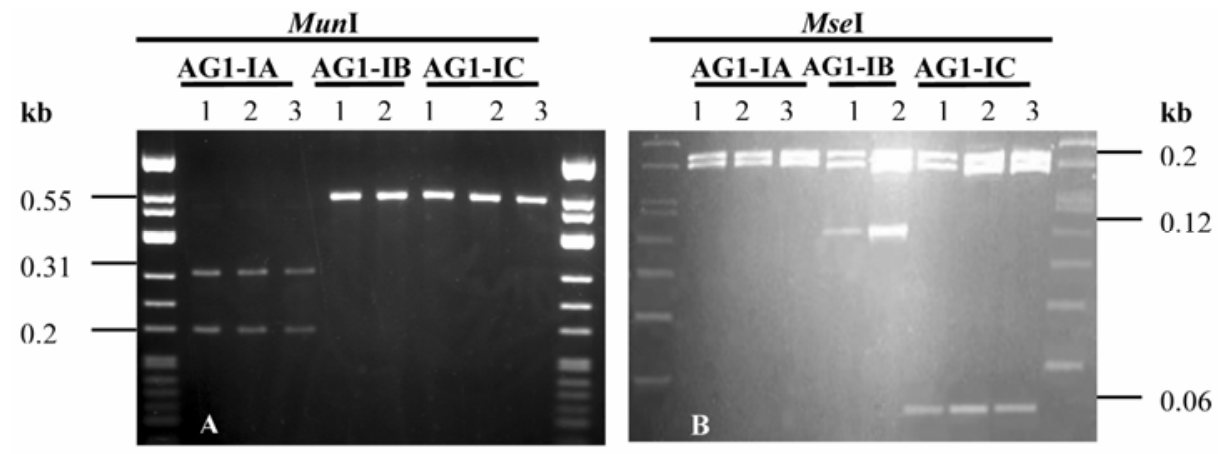

Fig. 2. Restriction patterns obtained by restriction fragment length polymorphism analysis of the internal transcribed spacer region of Rhizoctonia solani AG1 isolates amplified with primers RS1 and RS4 and digested with A, MunI or B, MseI. Lanes that contain AG1-IA isolates are: lane 1, NL-104; lane 2, KAL-32; and lane 3, CSKA (AG1-IA tester isolate). Lanes that contain AG1-IB isolates are: lane 1, KKD-1.12; and lane 2, B19 (AG1-IB tester isolate). Lanes that contain AG1IC isolates are: lane 1, KKD-1.23; lane 2, PTB-48; and lane 3, BV17 (AG1-IC tester isolate). Molecular weight marker 10 was run in the first and last lanes.

TABLE 2. Selected primer combinations and polymorphism rates for amplified fragment length polymorphism analysis of 110 Rhizoctonia isolates representing two species associated with rice sheath diseases

\begin{tabular}{|c|c|c|c|c|c|c|c|}
\hline \multirow[b]{2}{*}{ Primer pairs } & \multirow[b]{2}{*}{$\begin{array}{l}\text { Total number } \\
\text { of bands }\end{array}$} & \multicolumn{3}{|c|}{ Complete data set (110 isolates) } & \multicolumn{3}{|c|}{ R. solani, AG1-IA (96 isolates) } \\
\hline & & $\begin{array}{c}\text { Scored } \\
\text { bands }\end{array}$ & $\begin{array}{l}\text { Polymorphic } \\
\text { bands }\end{array}$ & $\begin{array}{c}\text { Polymorphism } \\
(\%)\end{array}$ & $\begin{array}{c}\text { Scored } \\
\text { bands }\end{array}$ & $\begin{array}{l}\text { Polymorphic } \\
\text { bands }\end{array}$ & $\begin{array}{c}\text { Polymorphism } \\
(\%)\end{array}$ \\
\hline $\mathrm{E}+\mathrm{CA} / \mathrm{M}+\mathrm{AT}$ & 102 & 50 & 45 & 90 & 50 & 45 & 90 \\
\hline $\mathrm{E}+\mathrm{CA} / \mathrm{M}+\mathrm{GC}$ & 114 & 88 & 76 & 86 & 80 & 66 & 82 \\
\hline $\mathrm{E}+\mathrm{CA} / \mathrm{M}+\mathrm{GT}$ & 129 & 93 & 82 & 88 & 90 & 73 & 81 \\
\hline Total & 443 & 292 & 255 & 87 & 278 & 235 & 84 \\
\hline
\end{tabular}




\section{Coefficient}

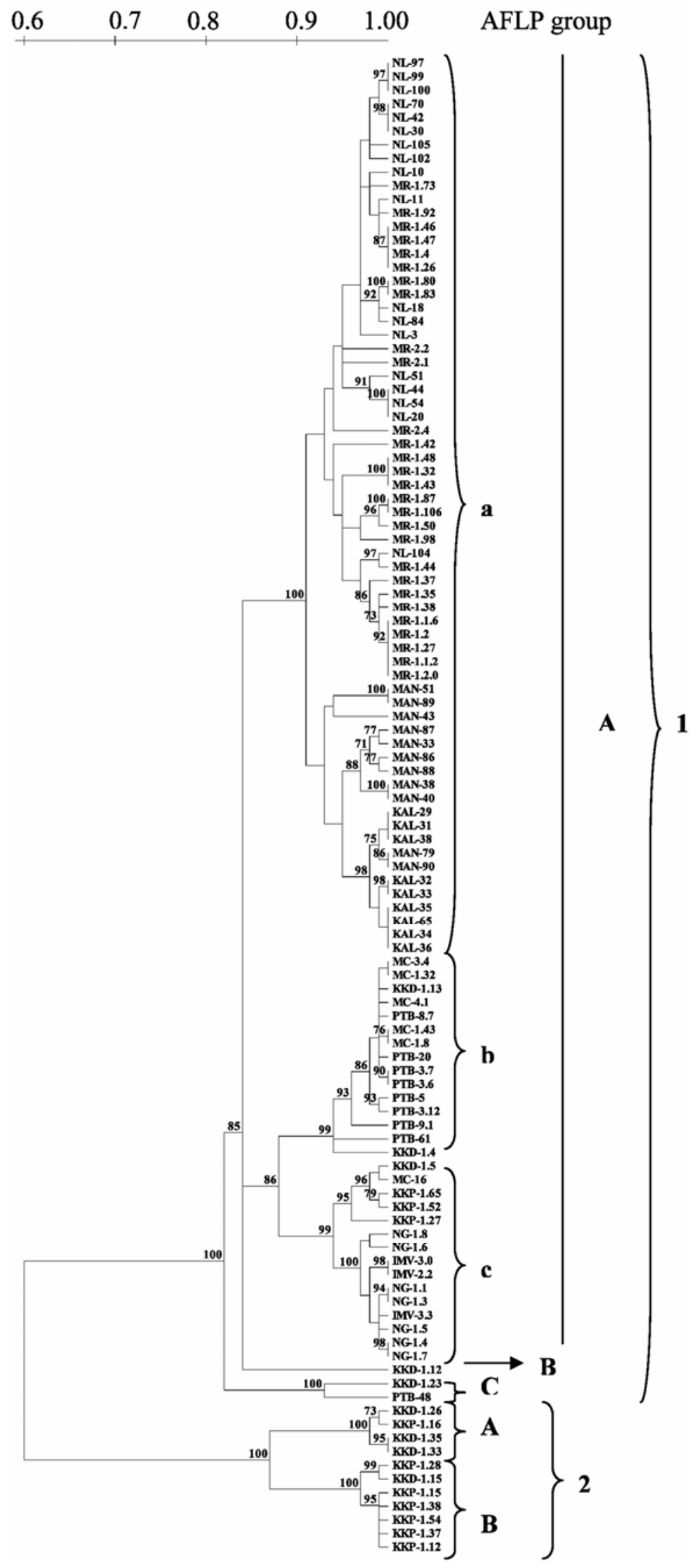

Fig. 3. Unweighted pair-group method, arithmetic mean dendrogram produced from amplified fragment length polymorphism (AFLP) fingerprint patterns observed for 110 Rhizoctonia spp. isolates. Scale bar indicates the horizontal distance corresponding to genetic similarity as measured by the Nei and Li similarity coefficient (29). Bootstrap values greater than 70 are indicated adjacent to the nodes and are based on 1,000 replications. 
The AFLP data were used to make pairwise comparisons of the genotypes to generate a similarity matrix based on both shared and unique amplification products. The correlation between the different genetic similarity matrices, obtained from the four separate primer pairs, was evaluated. The lowest correlation was observed between the similarity matrices generated by the primer pairs $\mathrm{E}+\mathrm{CA} / \mathrm{M}+\mathrm{GT}$ and $\mathrm{E}+\mathrm{CA} / \mathrm{M}+\mathrm{AT}(\mathrm{r}=0.42)$. Although each primer pair individually could have given an approximation of the entire data set, sufficient differences existed between them. Therefore the data obtained from all four primer pairs was used in the analysis. For dendrograms resulting from any of the various similarity matrices (Jaccard's or Nei and Li's) in combination with the different clustering methods (UPGMA, WPGMA, complete linkage, or single linkage), the goodness of fit of the clustering to the data matrix was evaluated. The cophenetic correlation coefficient for each of the generated dendrograms was determined and compared (data not shown). Application of the UPGMA clustering method gave the highest cophenetic correlation coefficients, where $r>0.9$ indicates a very good fit; $0.8<\mathrm{r}<0.9$ indicates a good fit; and $\mathrm{r}<0.8$ indicates a weak fit. The Nei and Li similarity matrix derived from the entire data set (292 scored markers) resulted in a high correlation value $(r=$ 0.985) that was comparable with the one calculated using Jaccard's coefficient (0.984). Comparing all the dendrograms generated, and selecting the cutoff points depending on the similarity coefficient and the clustering method employed, the two species ( $R$. solani and $R$. oryzae-sativae) and three ISGs of $R$. solani AG1 (IA, IB, and IC) clearly clustered separately. Also, the species and ISGs relationships obtained using Treecon with the Nei and Li coefficient (29) (Fig. 3) were similar to those obtained using UPGMA, except for minor differences in branch lengths and a topological rearrangement where lineage 1Ac clustered between lineages $1 \mathrm{Aa}$ and $1 \mathrm{Ab}$ in the dendrograms obtained using UPGMA (data not shown).

Genetic structure of Rhizoctonia spp. populations from rice in India. AMOVA was used to assess genetic variability within $R$. solani AG1-IA. First, genetic variability distribution among and within 4 different states (Andhra Pradesh, Karnataka, Kerala, and Tamil Nadu) was estimated. Subsequently, two subgroups were defined to compare AG1-IA isolates of Andhra Pradesh with isolates obtained from the three other states. Also, genetic variability distribution among and within 13 rice cultivars (cultivars ADT-24, HR-12, IR-20, IR-36, IR-50, Mukamala, Neeraja, Pavizham, Pokkali-04, PTB-9, M. Vijaya, Sania, and Swarna) was estimated. For clone-corrected data, the first two levels AMOVA (Table 3) of all $R$. solani AG1-IA isolates from four sampling states revealed $56.21 \%$ of the total variation within (intra) states and $43.79 \%$ among (inter) states. Using clonecorrected data, the second two levels AMOVA partitioned $29.68 \%$ of genetic variation among the two subgroups defined (to separate and compare the isolates of Andhra Pradesh with other states), and $70.32 \%$ within subgroups. All $P$ values were statistically significant $(P<0.0001)$, indicating that the geographic region is a significant force in determining the genetic structure of these populations. Especially, the second two levels AMOVA revealed a significant difference between isolates of Andhra Pradesh and other states. When groups of populations differing in host cultivar were compared in the three levels AMOVA (Table 3), difference among cultivars was not significant, indicating host cultivar is not a selective force influencing population structure. Based on the AFLP tree, the AMOVA analysis was repeated after defining five geographic locations (Andhra Pradesh, Karnataka MAN and KAL, Karnataka NG and IMV, Kerala, and Tamil Nadu) instead of four (first two levels AMOVA), and defining two subgroups consisting of isolates from Andhra Pradesh and Karnataka MAN and KAL, on one hand and isolates from Karnataka NG and IMV, Kerala, and Tamil Nadu on the other hand (second two levels AMOVA). For clone-corrected data, the percentages of variation were 60.91 and $39.09 \%$ among and within locations, respectively. The second two levels AMOVA partitioned 51.25\% among the two subgroups defined and $48.75 \%$ within subgroups. All $P$ values were statistically significant $(P<0.0001)$ (Table 4$)$.

These results indicate that two populations can be distinguished in the isolates of Karnataka: One population includes isolates obtained from KAL and MAN locations, while the second population includes isolates from IMV and NG locations.

To further investigate the genetic structure of $R$. solani AG1-IA isolates, genetic similarity values of AG1-IA isolates belonging to Andhra Pradesh, Karnata (KAL and MAN), Karnataka (IMV and NG), Kerala, and Tamil Nadu were compared. Average genetic similarities among all $R$. solani AG1-IA isolates ranged from 0.80 (between isolates of Andhra Pradesh and Karnataka isolates collected in IMV and NG locations) to 0.91 (between isolates of Andhra Pradesh and Karnataka collected in KAL and MAN locations) (Table 5). When all AG1-IA isolates were considered, the mean genetic similarity value of AG1-IA isolates was 0.87 .

Pathogenicity tests. All isolates tested were pathogenic to rice. Control plants that were inoculated with noncolonized toothpicks did not show any symptoms. Isolates of $R$. solani AG1-IA induced typical rice sheath blight symptoms of ellipsoidal shape, 1.5 to $6 \mathrm{~cm}$ in length, with an initially greenish, but later gray, center, and a dark brown margin. In contrast, the AG1-IB isolate induced leaves to turn yellow and caused

TABLE 3. Analysis of molecular variance based on 292 amplified fragment polymorphism bands among Rhizoctonia solani AG1-IA isolates from four different states in India or from 13 different rice cultivars

\begin{tabular}{|c|c|c|c|c|c|c|}
\hline Source of variation & $\mathrm{df}^{\mathrm{a}}$ & $\%$ of total & $P$ value ${ }^{\mathrm{b}}$ & $\mathrm{df}^{\mathrm{c}}$ & $\%$ of total & $P$ value \\
\hline \multicolumn{7}{|l|}{ First two levels } \\
\hline Among states ${ }^{\mathrm{d}}$ & 3 & 46.94 & $<0.0001$ & 3 & 43.79 & $<0.0001$ \\
\hline Within states & 92 & 53.06 & $<0.0001$ & 62 & 56.21 & $<0.0001$ \\
\hline Among subgroups ${ }^{\mathrm{e}}$ & 1 & 28.78 & $<0.0001$ & 1 & 29.68 & $<0.0001$ \\
\hline Within subgroups & 94 & 71.22 & $<0.0001$ & 64 & 70.32 & $<0.0001$ \\
\hline \multicolumn{7}{|l|}{ Three levels } \\
\hline
\end{tabular}

${ }^{a}$ Data from all 96 R. solani AG1-IA isolates were used (uncorrected data).

${ }^{\mathrm{b}}$ Probability of a larger value obtained by chance, determined by 1,000 permutations of the data set.

${ }^{c}$ One isolate per genotype was retained in each defined group (clone-corrected data, including 64 isolates).

d One group of $R$. solani AG1-IA isolates was defined consisting of four sampling states (Andhra Pradesh, Karnataka, Kerala, and Tamil Nadu).

${ }^{\mathrm{e}}$ One group of isolates was defined consisting of two subgroups: isolates of Andhra Pradesh, and isolates from other states.

${ }^{\mathrm{f}}$ Thirteen groups of $R$. solani AG1-IA isolates were defined based on the rice cultivars. Each group consisted of isolates collected from the same cultivar, with isolates of different geographic locations separately defined and analyzed. 
ellipsoid lesions, 1.5 to $4.5 \mathrm{~cm}$ in length, with an initially greenish, but later gray, center, and a light brown margin.

The isolates of AG1-IC caused small, circular-to-ellipsoid lesions with a length of 0.5 to $1 \mathrm{~cm}$ and a brown margin. $R$. oryzae-sativae isolates induced typical rice aggregate sheath spot symptoms of ellipsoid lesions with gray/green-to-straw colored centers surrounded by distinct brown margins. Additional margins formed around the lesion, producing series of concentric rings. Initial lesions range in length from about 1 to $4 \mathrm{~cm}$ (Fig. 4). However, there was considerable variation in virulence among isolates on rice. $R$. solani AG1-IA isolate NL-104, collected from Andhra Pradesh, was the most virulent, with a relative lesion height (RLH) of $75.56 \%$ (Table 6). In general, isolates of $R$. solani AG1-IA and the single isolate of AG1-IB caused more severe infection on rice than isolates of $R$. solani AG1-IC and $R$. oryzae-sativae. Two groups of $R$. oryzae-sativae isolates identified by AFLP (Fig. 3, 2A and B) showed significant differences in virulence, and isolates of lineage $2 \mathrm{~A}$ were more virulent than lineage 2B (Table 6). Two isolates of AG1-IC showed the lowest level of virulence among all isolates tested.

\section{DISCUSSION}

Our results indicate that multinucleate $R$. solani AG1-IA was the established, and perhaps the predominant, AG1 subgroup causing rice sheath blight in the warm, rice-growing areas of India. In addition, we provided evidence that rice sheath diseases in India can also be caused by $R$. solani AG1-1B, AG1-1C, and binucleate $R$. oryzae-sativae. It has been already shown that $R$. solani AG1-1A and $R$. oryzae-sativae can cause sheath diseases on rice in India $(18,27)$.

A PCR-based method described by Johanson et al. (14) allowed rapid and accurate identification of the Rhizoctonia species responsible for rice sheath diseases in India and confirmed the results of morphological characterization of the isolates.

Isolates of AG1-IA, IB, and IC could not be differentiated by anastomosis grouping on a slide but PCR-RFLP (10) was useful in differentiating the three ISGs of AG1 in this study. Using two restriction enzymes, the fragment size of the rDNA-ITS region within ISGs of AG1 and restriction sites was the same as that found by Guillemaut et al. (10). However no genetic differences in the restriction pattern of ITS region were observed among AG1-IA isolates. This may be because only isolates collected from rice were used. Guillemaut et al. (10) used AG1-IA isolates collected from different host plants in different countries and found a low level of polymorphism among them only with $\mathrm{Mse}$ I.

The AFLP analysis in the present study showed a clear link with the morphological and molecular characterization of the isolates. AFLP analysis separated Rhizoctonia isolates belonging to different species ( $R$. solani and $R$. oryzae-sativae) and ISGs of
$R$. solani AG1. Also, AFLP results revealed the genetic differentiation between $R$. solani and $R$. oryzae-sativae, and the close relationship among three ISGs of $R$. solani AG1. The level of genetic variability detected within the Rhizoctonia isolates by AFLP analysis confirmed that it is a reliable, efficient, and effective marker technology for determining genetic relationships in Rhizoctonia spp. In addition, we have shown that AFLP analysis provides a useful method for identification of genetically distinct individuals in populations of $R$. solani AG1-1A associated with rice sheath blight as described previously for populations of $R$. solani AG-3 from potato and tobacco (5). All $R$. solani AG1-IA isolates linked at $84 \%$ similarity level, which was lower than previously found in India (95\%) using Rep-PCR fingerprinting (18). These findings could indicate that the AFLP fingerprint technique utilized in this study can detect more genetic variation than can Rep-PCR. The relatively high genetic differentiation in the isolates of $R$. solani AG1-IA from rice in India observed in the present study is in agreement with another study of $R$. solani AG1-IA from a field in Cote d'Ivoire, using SSR-PCR (2). Also, our results are in agreement with the study of $R$. solani AG1-IA from rice in Texas (34), using RFLP fingerprint probes, indicating high genetic diversity coupled with gene flow in the populations of this pathogen, as explained by Anderson and Kohn (1). They write that most fungal populations occupy an intermediate position between gene flow (clonality) and random mating (panmixia) or outcrossing, with some levels of clonal reproduction and some genetic exchange and recombination. When the clonal part of reproduction is subtracted from a mixed system, genetic variation may be random or partitioned, for instance, by host or geographic origin (1).

The same AFLP genotype was only found among isolates originating from the same geographic location. Clones with identical AFLP genotypes were found in sampling sites of the same rice field separated by $5 \mathrm{~m}$ (in the case of isolates KAL-32 and KAL-33) to $500 \mathrm{~m}$ (in the case of KAL-65 and other isolates

TABLE 5. Genetic similarity values based on the Nei and Li coefficient (28) between (upper triangle) and within (diagonal) the different groups of Rhizoctonia solani AG1-IA isolates, based on all pairwise similarities between individuals using amplified fragment length polymorphism data

\begin{tabular}{lccccc}
\hline State $^{\mathrm{a}}$ & AP & Kar KM & Kar IN & Ker & TN \\
\hline AP $\left(n^{\mathrm{b}}=46\right)$ & 0.92 & 0.91 & 0.80 & 0.81 & 0.83 \\
Kar KM $(n=20)$ & & 0.92 & 0.82 & 0.82 & 0.82 \\
Kar IN $(n=10)$ & & & 0.96 & 0.86 & 0.87 \\
Ker $(n=14)$ & & & & 0.87 & 0.88 \\
TN $(n=6)$ & & & & & 0.93 \\
\hline
\end{tabular}

a AP = Andhra Pradesh, Kar KM = Karnataka (KAL and MAN locations), Kar

IN = Karnataka (IMV and NG locations), Ker = Kerala, and TN = Tamil Nadu.

b Number of isolates.

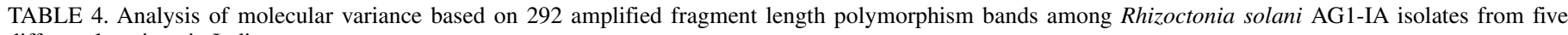
different locations in India

\begin{tabular}{|c|c|c|c|c|c|c|}
\hline Source of variation & $\mathrm{df}^{\mathrm{a}}$ & $\%$ of total & $P$ value ${ }^{\mathrm{b}}$ & $\mathrm{df}^{\mathrm{c}}$ & $\%$ of total & $P$ value \\
\hline \multicolumn{7}{|l|}{ First two levels } \\
\hline Among locations ${ }^{\mathrm{d}}$ & 4 & 63.40 & $<0.0001$ & 4 & 60.91 & $<0.0001$ \\
\hline Within locations & 91 & 36.60 & $<0.0001$ & 60 & 39.09 & $<0.0001$ \\
\hline \multicolumn{7}{|l|}{ Second two levels } \\
\hline Among subgroups ${ }^{\mathrm{e}}$ & 1 & 53.78 & $<0.0001$ & 1 & 51.25 & $<0.0001$ \\
\hline Within subgroups & 94 & 46.22 & $<0.0001$ & 64 & 48.75 & $<0.0001$ \\
\hline
\end{tabular}

a Data from all 96 R. solani AG1-IA isolates were used (uncorrected data).

b Probability of a larger value obtained by chance, determined by 1,000 permutations of the data set.

${ }^{c}$ One isolate per genotype was retained in each defined group (clone-corrected data including 64 isolates).

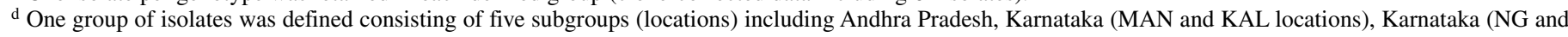
IMV locations), Kerala, and Tamil Nadu.

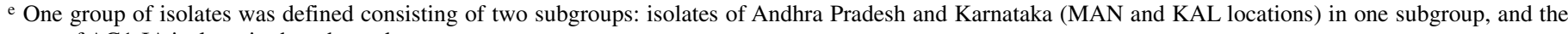
rest of AG1-IA isolates in the other subgroup. 
of the same clone: KAL-34, KAL-35, and KAL-36). Two clones from NL (consisting of isolates NL-44, NL-54, and NL-20) and MAN (isolates MAN-51 and MAN-89) locations, however, contained isolates that originated from different fields separated by 4 and $3 \mathrm{~km}$, respectively. This is evidence of dissemination of asexual propagules (sclerotia or mycelia) in MAN and NL populations over relatively long distances. Dissemination of asexual propagules is made possible by the transport of sclerotia or other asexual fungal structures in soil or infected organic material on agricultural machinery or other equipment, in irrigation water, and by contaminated seeds. Frequent dispersal of asexual propagules among populations would lead to widespread dispersal of clones across population (18). In PTB, MC, KKD, KKP, IMV, and NG populations of $R$. solani AG1-IA, we found no evidence for long-distance dispersal of asexual propagules, as isolates with the same genotype were only found in places 10 to $200 \mathrm{~m}$ apart. This is in agreement with the observations of Linde et al. (18), who differentiated some of the same isolates from the six above-mentioned locations using Rep-PCR fingerprinting. Isolates with the same genotype were only obtained from the same rice field at small distances from each other, which could be attributed to the relatively low sample sizes analyzed. This could indeed be the case, as our results revealed that in Andhra Pradesh, which was more widely sampled, isolates with the same genotype could be found in different rice fields. In another study in Texas, larger sample sizes were analyzed and clones were identified in populations separated by up to $280 \mathrm{~km}$ using an RFLP fingerprint probe (34).

AMOVA analysis revealed that the geographic region is the dominant force influencing the genetic structure of $R$. solani AG1-1A infecting rice in India. Significant differences among states were revealed. In addition, isolates of Andhra Pradesh, which originated from locations more distant from the three other states, were significantly different from isolates of other states. Host cultivar did not account for genetic variation according to AMOVA (Table 3).

Isolates of Karnataka from KAL and MAN locations were more similar to Andhra Pradesh isolates compared to Karnataka isolates from IMV and NG locations, since they clustered together in the AFLP dendrogram with a bootstrap value of $100 \%$ (Fig. 3). Also, the genetic similarity value obtained between isolates of Karnataka (KAL and MAN) and Andhra Pradesh was 0.91, whereas the value between Karnataka (KAL and MAN) and Karnataka (IMV and NG) isolates was 0.82 (Table 5). Therefore, an additional AMOVA analysis was done in which AG1-IA isolates were divided into five subgroups that included isolates of Andhra Pradesh, Karnataka (KAL and MAN), Karnataka (IMV and NG), Kerala, and Tamil Nadu. Significant differences were observed among the subgroups (Table 4) and the percentage of variation within the five subgroups was lower than in the previous AMOVA in which all isolates from Karnataka were analyzed together (Table 3). In addition, AMOVA revealed significant differences between a subgroup that included isolates of Andhra Pradesh together with Karnataka (KAL and MAN) and another subgroup consisting of all other AG1-IA isolates. Based on these results, isolates from KAL and MAN locations of Karnataka appear to be genetically distinct from isolates from IMV and NG locations. Figure 1 shows that both KAL and MAN are located north of Cauvery (Kaveri) river, while IMV, ING, and the locations sampled in Kerala and Tamil Nadu are located south of this river. Cauvery is one of the three major rivers of India, and may form a natural barrier that prevents fungal dispersal and a high level of genetic exchange between the KAL-MAN population and populations south of Cauvery river. It is less likely that the genetic difference between the KAL-MAN and IMV-NG population is due to the year of sampling. KAL and MAN isolates were obtained in 2003. Yet these isolates are genetically similar to isolates from Andhra Pradesh that were obtained in 2001. Linde et al. (18) have studied the population structure of $R$. solani AG1-1A from eight locations south of Cauvery river (including isolates from PTB, MC, KKP, KKD, NG, and IMV that were also used in this study), using RFLP and Rep-PCR, and found low levels of population subdivision, and small genetic distances among populations. This could be due to possible long-distance dis-

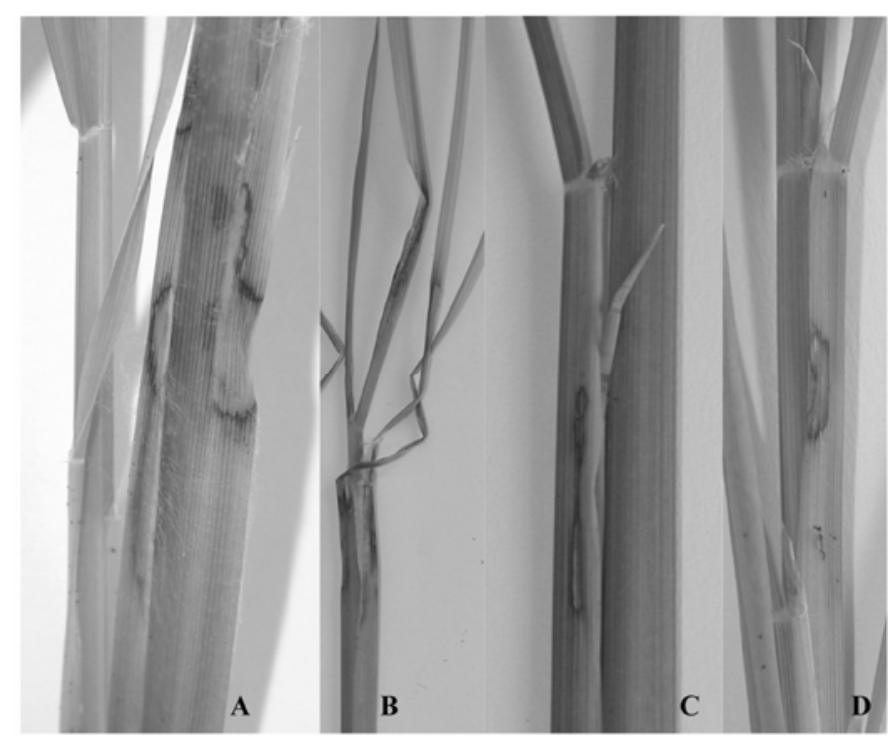

Fig. 4. Symptoms induced on rice (Oryza sativa cv. Zenith) 7 days after inoculation with Rhizoctonia spp. isolates: $\mathbf{A}$, typical rice sheath blight symptoms induced by isolate NL-104 ( $R$. solani AG1-IA); B, sheath blight symptoms induced by isolate $\mathrm{KKD}-1.12$ ( $R$. solani AG1-IB); C, weakly virulent response induced by isolate PTB-48 ( $R$. solani AG1-IC); and D, typical rice aggregate sheath spot symptoms induced by isolate KKD-1.35 (R. oryzae-sativae).

TABLE 6. Relative lesion height caused by Rhizoctonia spp. isolates on rice cv. Zenith

\begin{tabular}{|c|c|c|c|}
\hline Isolate & $\mathrm{TG}^{\mathrm{a}}$ & AFLP group ${ }^{b}$ & Mean RLH $(\%)^{\mathrm{c}}$ \\
\hline NL-104 & IA & $1 \mathrm{Aa}$ & $75.56 \mathrm{a}^{\mathrm{c}}$ \\
\hline KKD-1.12 & IB & 1B & $70.81 \mathrm{~b}$ \\
\hline MR-1.106 & IA & $1 \mathrm{Aa}$ & $62.19 \mathrm{c}$ \\
\hline MR-1.47 & IA & $1 \mathrm{Aa}$ & $56.19 \mathrm{~d}$ \\
\hline MR-1.4 & IA & $1 \mathrm{Aa}$ & $51.81 \mathrm{e}$ \\
\hline NL-102 & IA & $1 \mathrm{Aa}$ & $50.56 \mathrm{e}$ \\
\hline MAN-88 & IA & $1 \mathrm{Aa}$ & $46.87 \mathrm{f}$ \\
\hline MAN-86 & IA & $1 \mathrm{Aa}$ & $45.81 \mathrm{f}$ \\
\hline MAN-89 & IA & $1 \mathrm{Aa}$ & $45.75 \mathrm{f}$ \\
\hline KAL-33 & IA & $1 \mathrm{Aa}$ & $45.69 \mathrm{f}$ \\
\hline KAL-32 & IA & $1 \mathrm{Aa}$ & $45.66 \mathrm{f}$ \\
\hline KAL-36 & IA & $1 \mathrm{Aa}$ & $45.42 \mathrm{f}$ \\
\hline NG-1.6 & IA & $1 \mathrm{Ac}$ & $39.56 \mathrm{~g}$ \\
\hline KKP-1.65 & IA & $1 \mathrm{Ac}$ & $39.52 \mathrm{~g}$ \\
\hline PTB-3.12 & IA & $1 \mathrm{Ab}$ & $38.56 \mathrm{~g}$ \\
\hline MC-1.8 & IA & $1 \mathrm{Ab}$ & $34.81 \mathrm{~h}$ \\
\hline KKD-1.35 & ROS & $2 \mathrm{~A}$ & $29.00 \mathrm{i}$ \\
\hline KKD-1.33 & ROS & $2 \mathrm{~A}$ & $26.25 \mathrm{j}$ \\
\hline KKD-1.26 & ROS & $2 \mathrm{~A}$ & $25.94 \mathrm{j}$ \\
\hline KKP-1.16 & ROS & $2 \mathrm{~A}$ & $25.81 \mathrm{j}$ \\
\hline KKP-1.54 & ROS & $2 \mathrm{~B}$ & $22.94 \mathrm{k}$ \\
\hline KKP-1.12 & ROS & $2 \mathrm{~B}$ & $22.56 \mathrm{k}$ \\
\hline KKP-1.38 & ROS & $2 \mathrm{~B}$ & $22.12 \mathrm{k}$ \\
\hline KKP-1.15 & ROS & $2 B$ & $22.00 \mathrm{k}$ \\
\hline KKP-1.37 & ROS & $2 B$ & $21.62 \mathrm{kl}$ \\
\hline KKP-1.28 & ROS & $2 B$ & $19.87 \mathrm{~m}$ \\
\hline KKD-1.15 & ROS & $2 B$ & $19.75 \mathrm{~m}$ \\
\hline PTB-48 & $\mathrm{IC}$ & $1 \mathrm{C}$ & $7.87 \mathrm{n}$ \\
\hline KKD-1.23 & $\mathrm{IC}$ & $1 \mathrm{C}$ & $7.00 \mathrm{n}$ \\
\hline
\end{tabular}

a Taxonomic group.

b Amplified fragment length polymorphism group.

c Relative lesion height. Means in a column followed by the same letter are not significantly different according to Mann-Whitney comparison test $(\alpha=0.05)$. 
persal of basidiospores (39) (leading to regionally high levels of gene flow), sexual reproduction, and persistence of successful clones in subpopulations. It is likely that the similarity between the Andhra Pradesh population and the KAL-MAN population in Karnataka can be explained by similar mechanisms. Fungal propagul dispersal can cause the establishment of new genotypes into new locations through introduction, reproduction, and survival of the introduced organism. Therefore, it tends to keep geographically separate populations genetically interconnected $(6,33)$.

Pathogenicity tests on Oryza sativa cv. Zenith showed that $R$. solani AG1-IA and AG1-IB isolates were more virulent in comparison with $R$. solani AG1-IC and $R$. oryzae-sativae isolates. $R$. solani AG1-1A isolates from the Andhra Pradesh (collected from MR and NL locations) and Karnataka (collected from KAL and MAN locations) seem to be more virulent on average than isolates from other states.

In summary, we identified an optimal set of AFLP primer combinations suitable for the genetic characterization of Rhizoctonia spp. populations. Our results provide initial information on the occurrence of a relatively high level of genetic diversity affecting the population structure of Rhizoctonia spp. associated with rice sheath diseases, and revealed that not only $R$. solani AG1-IA and $R$. oryzae-sativa, but also $R$. solani AG1-IB and AG1-IC, are virulent on rice. Studies that incorporate larger sample sizes are needed to elucidate the genetic structure of $R$. oryzae-sativae and $R$. solani AG1-IB and AG1-IC, which are less studied. In particular, pathogen populations should be monitored to determine if new genotypes have been introduced into a region over time. More focus on the genetic structure of Rhizoctonia pathogens of rice is necessary in order to compare population structure and biological evolution of different taxonomic groups of these important soilborne pathogens.

\section{ACKNOWLEDGMENTS}

We thank J. H. M. Schneider (ISR sugar beet pathology / pests, Bergen op Zoom, the Netherlands) for providing tester isolates of $R$. solani; and T. Kyndt (Ghent University, Ghent, Belgium) for critical reading of the manuscript. P. Taheri was supported by a Ph.D. grant from the Ministry of Science, Research, and Technology, Iran.

\section{LITERATURE CITED}

1. Anderson, J. B., and Kohn, L. M. 1995. Clonality in soilborne, plantpathogenic fungi. Annu. Rev. Phytopathol. 33:369-391.

2. Banniza, S., and Rutherford, M. A. 2001. Diversity of isolates of Rhizoctonia solani AG-1 IA and their relationship to other anastomosis groups based on pectic zymograms and molecular analysis. Mycol. Res. 105:33-40.

3. Banniza, S., Sy, A. A., Bridge, P. D., Simons, S. A., and Holderness, M. 1999. Characterization of populations of Rhizoctonia solani in paddy rice fields in Cote d' Ivoire. Phytopathology 89:414-420.

4. Carling, D. E. 1996. Grouping in Rhizoctonia solani by hyphal anastomosis. Pages 37-47 in: Rhizoctonia Species: Taxonomy, Molecular Biology, Ecology, Pathology, and Disease Control. B. Sneh, S. JabajiHare, S. Neate, and G. Dijst, eds. Kluwer Academic Publishers, Dordrecht, the Netherlands.

5. Ceresini, P. C., Shew, H. D., Vilgalys, R. J., and Cubeta, M. A. 2002. Genetic diversity of Rhizoctonia solani AG-3 from potato and tobacco in North Carolina. Mycologia 94:437-449.

6. Ceresini, P. C., Shew, H. D., Vilgalys, R., Gale, L. R., and Cubeta, M. A. 2003. Detecting migrants in populations of Rhizoctonia solani anastomosis group 3 from potato in North Carolina using multilocus genotype probabilities. Phytopathology 93:610-615.

7. Excoffier, L., Smouse, P. E., and Quattro, J. M. 1992. Analysis of molecular variance inferred from metric distances among DNA haplotypes: Application to human mitochondrial DNA restriction sites. Genetics 131:479-491.

8. Felsenstein, J. 1985. Confidence limits on phylogenies: An approach using the bootstrap. Evolution 39:783-791.
9. Gangopadhay, S., and Chakrabarti, N. K. 1982. Sheath blight on rice. Rev. Plant Pathol. 61:451-460.

10. Guillemaut, C., Herman, V. E., Camporota, P., Alabouvette, C., Molard, M. R., and Steinberg, C. 2003. Typing of anastomosis groups of Rhizoctonia solani by restriction analysis of ribosomal DNA. Can. J. Microbiol. 49:556-568.

11. Gunnell, P. S., and Webster, R. K. 1984. Aggregate sheath spot of rice in California. Plant Dis. 68:529-531.

12. Highton, R. 1993. The relationship between the number of loci and the statistical support for the topology of UPGMA trees obtained from genetic distance data. Mol. Phylog. Evol. 2:337-343.

13. Jaccard, P. 1908. Nouvelles recherches sur la distribution florale. Bull. Soc. Vaud. Sci. Nat. 44:223-270.

14. Johanson, A., Turner, H. C., McKay, G. J., and Brown, A. E. 1998. A PCR-based method to distinguish fungi of the rice sheath-blight complex, Rhizoctonia solani, R. oryzae, and R. oryzae-sativae. FEMS Microbiol. Lett. 162:289-294.

15. Jones, R. K., and Belmar, S. B. 1989. Characterization and pathogenicity of Rhizoctonia spp. isolates from rice, soybean, and other crops grown in rotation with rice in Texas. Plant Dis. 73:1004-1010.

16. Kobayashi, T., Mew, T. W., and Hashiba, T. 1997. Relationship between incidence of rice sheath blight and primary inoculum in the Philippines: Mycelia in plant debris and sclerotia. Ann. Phytopathol. Soc. Jpn. 63:324327.

17. Lance, G. N., and Williams, W. T. 1967. A general theory of classificatory sorting strategies. 1. Hierarchical systems. Computer J. 9:373-380.

18. Linde, C. C., Zala, M., Paulraj, R. S. D., McDonald, B. A., and Gnanamanickam, S. 2005. Population structure of the rice sheath blight pathogen Rhizoctonia solani AG-1IA from India. Eur. J. Plant Pathol. 112:113-121.

19. Liu, Z. L., and Sinclair, J. B. 1993. Differentiation of intraspecific groups within anastomosis group 1 of Rhizoctonia solani using ribosomal DNA internal transcribed spacer and isozyme comparison. Can. J. Plant Pathol. 15:272-280.

20. Lynch, M., and Milligan, B. 1994. Analysis of population genetic structure with RAPD markers. Mol. Ecol. 3:91-99.

21. Mantel, N. A. 1967. The detection of disease clustering and a generalized regression approach. Cancer Res. 27:209-220.

22. Marshall, D. S., and Rush, M. C. 1980. Relation between infection by Rhizoctonia solani and $R$. oryzae and disease severity in rice. Phytopathology 70:941-946.

23. Martin, S. B., and Lucas, L. T. 1984. Characterization and pathogenicity of Rhizoctonia spp. and binucleate Rhizoctonia-like fungi from turfgrasses in North Carolina. Phytopathology 74:170-175.

24. Matsuyama, N., Moromizato, Z., Ogoshi, A., and Wakimoto, S. 1978. Grouping Rhizoctonia solani with non-specific esterase zymogram. Ann. Phytopathol. Soc. Jpn. 44:652-658.

25. Mohammadi, M., Banihashemi, M., Hedjaroude, G. A., and Rahimian, H. 2003. Genetic diversity among Iranian isolates of Rhizoctonia solani anastomosis group 1 subgroups based on isozyme analysis and total soluble protein pattern. J. Phytopathol. 151:162-170.

26. Muller, U. G., and Wolfenbarger, L. L. 1999. AFLP genotyping and fingerprinting. Trends Ecol. Evol. 14:389-394.

27. Neeraja, C. N., Shenoy, V. V., Reddy, C. S., and Sarma, N. P. 2002. Isozyme polymorphism and virulence of Indian isolates of the rice sheath blight fungus. Mycopathologia 159:101-108.

28. Neeraja, C. N., Vijayabhanu, N., Shenoy, V. V., Reddy, C. S., and Sarma, N. P. 2002. RAPD analysis of Indian isolates of rice sheath blight fungus Rhizoctonia solani. J. Plant Biochem. Biotech. 11:43-48.

29. Nei, M., and Li, W. H. 1979. Mathematical model for studying genetic variation in terms of restriction endonucleases. Proc. Natl. Acad. Sci. USA 76:5267-5273.

30. Ogoshi, A. 1987. Ecology and pathogenicity of anastomosis and intraspecific groups of Rhizoctonia solani. Ann. Rev. Phytopathol. 25:125-143.

31. Rodrigues, F. A., Datnoff, L. E., Korndorfer, G. H., Seebold, K. W., and Rush, M. C. 2001. Effect of silicon and host resistance on sheath blight development in rice. Plant Dis. 85:827-832.

32. Rodrigues, F. A., Vale, F. X. R., Datnoff, L. E., Prabhu, A. S., and Korndorfer, G. H. 2003. Effect of rice growth stages and silicon on sheath blight development. Phytopathology 93:256-261.

33. Rogers, S. O., and Rogers, M. A. M. 1999. Gene flow in fungi. Pages 97-121 in: Structure and Dynamics of Fungal Populations. J. J. Worrall, ed. Kluwer Academic Publishers, Dordrecht, the Netherlands.

34. Rosewich, U. L., Pettway, R. E., McDonald, B. A., and Kistler, H. C. 1999. High levels of gene flow and heterozygote excess characterize Rhizoctonia solani AG-1 IA (Thanatephorus cucumeris) from Texas. Fungal Genet. Biol. 28:148-159.

35. Savary, S., Castilla, N. P., Elazegui, F. A., McLaren, C. G., Ynalvez, M. A., and Teng, P. S. 1995. Direct and indirect effects of nitrogen supply and 
disease source structure on rice sheath blight spread. Phytopathology 85:959965.

36. Schneider, S. Roessli, D., and Excoffier, L. 2000. Arlequin: A software for population genetics data analysis, version 2.0. Univ. Geneva, Switzerland.

37. Sharma, N. R., Teng, P. S., and Olivares, F. M. 1990. Comparison of assessment methods for rice sheath blight disease. Phillipp. Phytopathol. 26:20-24.

38. Sherwood, R. T., 1969. Morphology and physiology in four an-astomosis groups of Thanatephorus cucumeris. Phytopathology 59:1924-1929.

39. Shew, H. D. 1985. Rhizoctonia leaf spot of flue-cured tobacco in North Carolina. Plant Dis. 69:901-903.

40. Sneath, P. H., and Sokal, R. R. 1973. Numerical Taxonomy. W. H. Freeman and Co., San Francisco.

41. Sneh, B., Burpee, L., and Ogoshi, A. 1991. Identification of Rhizoctonia Species. The American Phytopathological Society, St. Paul, MN.

42. Sokal, R. R., and Michener, C. D. 1958. A statistical method for evaluating systematic relationships. Univ. Kan. Sci. Bull. 38:1409-1438.
43. Stevens Johnk, J., and Jones, R. K. 1994. Comparison of whole-cell fatty acid compositions in intra-specific groups of Rhizoctonia solani AG-1. Phytopathology 84:271-275.

44. Vijayan, M., and Nair, C. M. 1985. Anastomosis group of iso-lates of Rhizoctonia solani (Thanatephorus cucumeris) caus-ing sheath blight of rice. Curr. Sci. 54:289-291.

45. Vos, P., Hogers, R., Bleeker, M., Reijans, M., Van de Lee, T., Hornes, M., Frijters, A., Pot, J., Peleman, J., Kuiper, M., and Zebeau, M. 1995. AFLP: a new technique for DNA fingerprinting. Nucleic Acids Res. 23:4407-4414

46. Zolan, M., and Pukkila, P. 1986. Inheritance of DNA methylation in Coprinus cinereus. Mol. Cell. Biol. 6:195-200.

47. Zuber, M., and Manibhushanrao, K. 1982. Studies on comparative gel electrophoretic patterns of proteins and enzymes from isolates of Rhizoctonia solani causing sheathblight disease in rice. Can. J. Microbiol. 28:762-771. 